\title{
Road Safety and Public Health in India
}

\author{
Ranabir Pal ${ }^{1}$ Amrita Ghosh ${ }^{2}$ Luis Rafael Moscote-Salazar ${ }^{3} \quad$ Amit Agrawal $^{4}$
}

\author{
${ }^{1}$ Department of Community Medicine, Mata Gujari Memorial \\ Medical College and LSK Hospital, Bihar, India \\ ${ }^{2}$ Department of Biochemistry, Medical College, Kolkata, India \\ ${ }^{3}$ Neurosurgery-Critical Care, Red Latino, Organización \\ Latinoamericana de Trauma y cuidado, Neurointensivo, \\ Bogota, Colombia \\ ${ }^{4}$ Department of Neurosurgery, All India Institute of Medical \\ Sciences, Madhya Pradesh, India
}

Indian J Neurotrauma:2021;18:86-87

Injuries place immense burdens on hospitals and health systems, and road crashes are preventable causes of injuries. ${ }^{1}$ Due to the ongoing socioeconomic and demographic changeover amid growing urbanization in India, road traffic injury (RTI) will hold fifth position as major killer by 2020 with an estimated 550,000 deaths.,3 From an agrarian base, India is in transition to an industrialized country with a very high productive population, which has resulted in an alarming increase in the use of mechanized transport. This has caused a spurt in vehicular density similar to other nations undergoing rapid economic growth. However, this spurt is so rapid that there is a gap to ensure road safety parameters. Additionally, there is global competition to invent increasingly sophisticated and faster vehicles, which becomes a cause for concern due to an increase in road crashes each year.

Official statistics in India regarding serious injuries out of the road crashes needs to be strengthened to estimate the actual number. ${ }^{4,5}$ There is a need to identify the reasons for underreporting, address the major challenges related to injury prevention, prehospital trauma care, and disability limitation. ${ }^{6}$ The first step in RTI prevention and safety is to identify risk factors at all levels of civilized society under the jurisdiction of the local governance. In this regard, there is a need to create awareness in the community, and identify the barriers and continuous positive efforts by local bodies to arrange regular sensitization programmes for the community. ${ }^{7,8}$ It is really interesting to note that roads in India are always repaired during or before monsoon; as a result, they have the potential to get washed away with the slightest showers. ${ }^{9}$

Research and action agenda suggested by the experts to confront disparities in addressing RTIs are as follows: establishment of routine collection and reporting of fatalities and nonfatal injuries from RTIs in low-income and middle-
Address for correspondence Ranabir Pal, MD (Preventive and Social Medicine), PhD, MBA, CMCL-FAIMER-Fellow, Department of Community Medicine, Mata Gujari Memorial Medical College and LSK Hospital, Kishanganj 855107, Bihar, India (e-mail: ranabirmon@yahoo.co.in).

income countries; and intervention strategies such as identification of interventions with flawless benefits to pedestrians, bicyclists, and motorcyclists and road users in low- and middle-income countries. ${ }^{7}$ There is an urgent need for the Union and provincial governments to spend more resources on road safety ranging from infrastructure to capacity building and scale up efforts for population-based national database on road crashes for proactive mitigation as well as effective intervention programmes. ${ }^{10-12}$ There will be a further need for a global plan to develop road safety management protocols, safer roads, mobility guidelines, and technologies to develop safer vehicles, ensuring awareness and safe use of roads and protocols to guide postcrash responses. ${ }^{1}$

\section{Funding}

None.

\section{Conflict of Interest}

None declared.

\section{References}

1 Robertson L. Ensuring the Decade Is Action. Decade of Action for Road Safety 2011-2020 [online]. Available at: http://siteresources.worldbank.org/EXTTOPGLOROASAF/ Resources/2582212-1265307800361/decade_of_action_2011. pdf. Accessed March 24, 2018

2 Pathak A, Desania NL, Verma R, Profile of Road Traffic Accidents \& Head Injury in Jaipur (Rajasthan). J Indian Acad Forensic Med 2008;30(1):6-9

3 Peden M, Scurfield R, Sleet DA, eds. World report on Road Traffic Injury Prevention 2004. World Health Organization Geneva. ISBN 9241562609 (NLM classification: WA 275)

4 Gururaj G, Thomas AA, Reddi M. Underreporting of road traffic injuries in Bangalore. Implications for road safety policies and programmes. Proceedings of the 5th world conference on injury prevention and control; 2000: Macmillan India Ltd New Delhi, India: 54

\section{published online}

September 23, 2020
Dol https://doi.org/

10.1055/s-0040-1713326

ISSN 0973-0508.
(C)2020. Neurotrauma Society of India.

This is an open access article published by Thieme under the terms of the Creative Commons Attribution-NonDerivative-NonCommercial-License, permitting copying and reproduction so long as the original work is given appropriate credit. Contents may not be used for commercial purposes, or adapted, remixed, transformed or built upon. (https://creativecommons.org/licenses/by-nc-nd/4.0/).

Thieme Medical and Scientific Publishers Pvt. Ltd. A-12, 2nd Floor, Sector 2, Noida-201301 UP, India 
5 Mohan D, The Road Ahead: Traffic Injuries and Fatalities in India. Transportation Research and Injury Prevention Programme. Delhi: Indian Institute of Technology; 2004;8

6 Pal R, Agarwal A, Galwankar S, et al. The 2014 Academic College of Emergency Experts in India's INDO-US Joint Working Group (JWG) white paper on "developing trauma sciences and injury care in India” Int J Crit Illn Inj Sci 2014;4(2):114-130

7 Agrawal A, Kakani A, Baisakhiya N, Galwankar S, Dwivedi S, Pal R. Developing traumatic brain injury data bank: prospective study to understand the pattern of documentation and presentation. The Indian Journal of Neurotrauma 2012;9:87-92

8 Dandona R, Kumar GA, Dandona L. Risky behavior of drivers of motorized two wheeled vehicles in India. J Safety Res 2006;37(2):149-158
9 Indian Driving School. Hurdles IDS in Road Safety - Indian Driving Schools [online]. Available at: http://www.indiandrivingschools.com/hurdles-in-road-safety.php. Accessed April 15,2020

10 Dandona R, Mishra A. Deaths due to road traffic crashed in Hyderabad city in India: need for strengthening surveillance. Natl Med J India 2004;17(2):74-79

11 Ramanujam P, Aschkenasy M. Identifying the need for prehospital and emergency care in the developing world: a case study in Chennai, India. J Assoc Physicians India 2007; 55:491-49

12 Basavaraj K, Venkatesh H, Rao GU. A prospective study of demography and outcome in operated head injuries. Indian J Anaesth 2005;49:24-30 